\title{
Cognitive functioning after subthalamic nucleotomy for refractory Parkinson's disease
}

\author{
Renee J McCarter, Nigel H Walton, Alison F Rowan, Stephen S Gill, Marina Palomo
}

\begin{abstract}
Objective-To evaluate whether subthalamic nucleotomy produces adverse cognitive effects in patients with Parkinson's disease.

Method-Twelve patients with Parkinson's disease underwent stereotactic surgery to the subthalamic nucleus. Presurgical and postsurgical neuropsychological assessment of attention, memory, executive function, language, and verbal intellect were undertaken with a battery of tests designed to minimise potential contamination of cognitive effects by motor symptoms.

Results-There was no statistically significant difference in the cognitive tests results after operation for the group as a whole. Reliable change indexes were generated for the cognitive tests. Reliable change postoperatively was found on specific tests of verbal memory, attention, and planning. Left sided operations were associated with greater incidence of deterioration postsurgery.

Conclusions-Preliminary data on the first reported cognitive changes after subthalamic nucleotomy suggested few adverse cognitive effects of the surgery although discrete neuropsychological changes were seen in some patients. These effects were consistent with current theories on the cognitive functions of the basal ganglia.
\end{abstract}

(F Neurol Neurosurg Psychiatry 2000;69:60-66)

Neuropsychology,

Frenchay Hospital, Frenchay Park Road, Bristol BS16 1LE, UK R J McCarter M Palomo

Department of Neurosurgery S S Gill

Department of Neuropsychology, Burden Neurological Hospital, Stapleton,

Bristol, UK

$\mathrm{N}$ H Walton

Wolfson Centre, Mecklenburgh Square, London, UK

A F Rowan

Correspondence to: R J McCarter

nhw@waisr.demon.co.uk

Received 21 May 1999 and in revised form

24 February 2000

Accepted 6 March 2000 subthalamic nucleus stimulation preferable to surgical ablation. ${ }^{6}$ However, the bulk, cost, need for regular replacement, and the potential for tolerance are disadvantages of stimulation. ${ }^{8}$ Gill and Heywood suggested that surgical procedures can also be used to reverse hemiballismus. ${ }^{8}$ They reported that small, well placed bilateral lesions in the caudomedial aspect of the subthalamic nucleus greatly improved the motor symptoms of two patients with refractory Parkinson's disease with no adverse effects and the benefits were maintained 16 months after the operation. The procedure is thought to be effective in reducing the outflow of excitatory activity from the subthalamic nucleus to the globus pallidus interna.

Parkinson's disease is recognised as primarily a disease of the basal ganglia. The functional anatomy of the basal ganglia may be defined in terms of five functional loops which comprise different feedforward and feedback pathways between the basal ganglia themselves and between the basal ganglia and other cortical structures. ${ }^{9}$ Disruption to these circuits may result in pure motor deficits (motor and oculomotor loops), cognitive deficits (dorsolateral and lateral orbitomedial prefrontal loops) or emotional deficits (limbic loop). ${ }^{10}$ The effects of Parkinson's disease on neuropsychological function, in addition to motor function, have been well established with reports of discrete impairments in visuospatial abilities, ${ }^{11} 12$ "frontal" functions, ${ }^{13-15}$ and memory. ${ }^{16}$ Many patients with Parkinson's disease do not show neuropsychological dysfunction but a significant proportion do show specific or even global cognitive and memory impairment in addition to motor symptoms. The aim of surgical ablation or electrical stimulation of the basal ganglia is the relief of motor symptoms, but such procedures have the potential to produce additional neuropsychological impairments as a consequence of disruption to the corticostriatal-thalamocortical loops. ${ }^{17-24}$

In early studies, thalamotomy and pallidotomy in Parkinson's disease were associated with neuropsychological morbidity. ${ }^{25}$ More recent studies of ablation and stimulation of the globus pallidus or thalamus have demonstrated variable outcomes with some reports of improved cognitive function ${ }^{27-30}$ and some reports of modest decline on specific neuropsychological measures, often related to the side of the lesion..$^{241-36}$ In many reports there was either no significant effect of surgery or the decline in individual test scores was reported as being functionally insignificant. ${ }^{23} 242833343738$ It is tempting to conclude that pallidotomy and pallidal stimulation for the relief of motor symptoms in refractory Parkinson's disease 
have no or very few significant adverse effects on cognitive functioning for most patients. There are, however, individual patients who show significant cognitive morbidity after such surgery, which points to a degree of heterogeneity of outcome, possibly related to the accuracy of localisation of lesions in individual cases. ${ }^{32}{ }^{33}$ Recent studies using volumetric MRI have found that lesion location, along the anteromedial to posterolateral axis within the globus pallidus interna, influences the outcome of surgery. ${ }^{39}$ Gross et al reported that placement of the lesion had a differential effect on relief of dyskinesia, rigidity, and gait problems in their group of 31 patients. ${ }^{39}$ They suggested that this was due to the presence of separate, parallel motor circuits within the globus pallidus and that symptom relief may be crucially related to precise lesion placement. Variability in outcome after pallidotomy may be partly due to location of lesions. If specific motor functions and symptoms of the disease may be differentially affected by the precise location of the lesion within the globus pallidus, then it may also be the case that specific cognitive effects might result from discrete lesions. Certainly, hemisphere specific cognitive changes have been reported after pallidotomy, suggesting the possibility of specific neuropsychological impairment as a direct consequence of the lesion. $^{31}$

Most recent studies have been concerned with the outcome of ablation or stimulation of the globus pallidus interna. Typically, patient numbers have been small. To our knowledge, there has been no systematic study of the effect of subthalamic nucleotomy on neuropsychological functioning in patients with Parkinson's disease.

The current study therefore reports the first data on the cognitive outcome of subthalamic nucleotomy for refractory Parkinson's disease. Patients were assessed just before surgery and a minimum of 3.5 months after surgery on a battery of neuropsychological tests designed to evaluate verbal and visual memory, aspects of attention and information processing, language, intellect, and executive or "frontal" functions. The tests were chosen specifically to minimise contamination from motor symptoms and to be clinically practicable for administration in this group of patients while providing a comprehensive assessment of higher cognitive function. Tests which tapped executive components of attention and memory were important to include in view of the potential for subthalamic nucleotomy to negatively impinge on frontostriatal or mamillothalamic neural circuits.

\section{Methods}

PARTICIPANTS

Participants in this study were 12 patients with refractory ideopathic Parkinson's disease who were admitted to the Frenchay Hospital, Bristol, UK for stereotactic subthalamic nucleotomy (STN). These patients represented a subgroup of a larger sample of patients referred to our centre for stereotactic surgery for Parkinson's disease, most of whom were initially considered for pallidotomy and were being investigated according to a standard pallidotomy trial protocol. Only those patients clearly identified as candidates for STN or subthalamic nucleus stimulation before referral for neuropsychological assessment are included in this study. These represent a consecutive series of 12 STN candidates who were able to complete most of the test battery before operation and to be reviewed less than 12 months after operation. Informed consent was obtained from all participants. All patients had disabling motor functioning despite optimal medication management. Patients were only included in the study if assessment by the consultant clinical neuropsychologist and consultant neurologist excluded a dementia or depressive illness. The patients were eight men and four women with an age range of 42 to 68 years at the time of operation. The mean duration of Parkinson's disease was 16.4 years with a range of 10 to 24 years. Two patients underwent a left sided STN, seven underwent a right sided STN, and three had bilateral procedures. Four of the patients with right sided STN also had a left subthalamic nucleus stimulator implanted concurrently.

SURGICAL PROCEDURE

The subthalamic nucleus was localised with high resolution MRI T2 sequences (1.5 Tesla TR 2,500, TE 150, TSE 11, NSA 12) and peroperative macrostimulation. Under general anaesthesia a modified Leksell stereotactic frame was fitted parallel to the orbitomeatal plane. The anterior-posterior commissural (AC-PC) plane was identified on a midsagittal planing scan. Axial images $2 \mathrm{~mm}$ thick were obtained parallel to the AC-PC plane and coronal images orthogonal to those were obtained. Boundaries of the subthalamic nucleus were then defined by reference to the magnified MRI and Schaltenbrand atlas. The dorsolateral portion of the subthalamic nucleus was the target of the stereotactic coordinates. At the time of surgery, all patients were awake and in an "off" state, their antiparkinsonian medications having been stopped 24 hours earlier. A $1.24 \mathrm{~mm}$ diameter electrode with a $2 \mathrm{~mm}$ exposed tip was guided to the dorsolateral subthalamic nucleus. The target was stimulated at $100 \mathrm{~Hz}, 1 \mathrm{~ms}$ pulse width, and between 0.75 and $2 \mathrm{~V}$ during which time change in tremor, rigidity, and bradykinesia was monitored. Probe position was adjusted to gain maximal clinical improvement without development of side effects. At the optimal position one or two radiofrequency lesions were made, typically at $80^{\circ} \mathrm{C}$ for 60 seconds. Postoperatively a high resolution MR scan was obtained to confirm lesion position and a course of dexamethasone for 24-48 hours was administered to reduce cerebral oedema. Antiparkinsonian medication was gradually reintroduced.

NEUROPSYCHOLOGICAL EVALUATION

Test battery

A comprehensive battery of tests was administered to obtain data on various cognitive and memory functions with as little contamination from motor dysfunction as possible. The test 
battery had to be practical for administration during a 2 hour window between admission, motor assessment, and cessation of medication. Even so, occasionally a test could not be completed due to the onset of akinesia or dyskinesia which affected speech or motor responses. We administered the national adult reading test-2 (NART) ${ }^{40}$ as an estimate of premorbid functioning. The following tests were administered both before surgery and at follow up: a short form of the verbal scale of the Wechsler adult intelligence scale-revised (WAIS-R $)^{41}$ to measure general verbal intelligence; The ${ }^{\star}$ Rey auditory verbal learning test $\left(\right.$ RAVLT) ${ }^{42}$ to measure complex verbal learning (trials 1-5) and retention (trial 6); the ${ }^{\star}$ Rivermead behavioural memory test story memory (immediate and delayed conditions) ${ }^{43}$ to measure contextual verbal learning and retention; the ${ }^{\star}$ release from proactive inhibition procedure to measure verbal encoding and executive aspects of verbal memory; the ${ }^{\star}$ Rivermead behavioural memory test facial recognition ${ }^{43}$ to measure visual memory; the attention/ concentration index from the Wechsler memory scale-revised (WMS-R A/C) ${ }^{44}$ to measure simple auditory and visual attention; the Stroop colour-word task ${ }^{45}$ to measure complex focused and sustained attention and inhibition; the paced serial addition test ( PASAT 2.0 second pacing $)^{46}$ to measure complex divided attention; the ${ }^{\star}$ controlled oral word association test (COWAT) ${ }^{47}$ to measure phonemic verbal fluency; and the five point test ${ }^{48}$ to measure design fluency. We adapted one commonly used "executive" test of spatial working memory and planning, the Tower of London test, ${ }^{49}$ so that demands on motor dexterity were minimised and we refer to this test as the Burden balls. The Tower of London test was originally devised as a test of planning and required patients to rearrange three coloured balls on three pegs of varying heights to match a presented "goal". Moves are governed by a set of simple rules. There are different standardisations of the task and it has been adapted for computer presentation. We wanted to preserve the manual mode of presentation but to minimise confounding effects of the movement disorders of our patients. To this end, the balls and pegs were replaced with two dimensional discs and slots so that the patients could simply slide the discs from one position to another with minimal demands on fine motor dexterity. The standard instructions, items, and scoring method developed by Anderson et $a l^{50}$ were employed. Total time taken to complete all items and number of correct items were recorded before and after surgery for each patient. In an effort to measure complex divided attention, we utilised the paced auditory serial addition task but chose only to administer one trial of 60 items for comparison before and after surgery. Our past experience with patients with Parkinson's disease had shown that the 2.0 second pacing was appropriate for most patients whereas slow speech and dysarthria contaminates the results for the faster 1.6 and 1.2 second pacings. Where possible, alternate forms of tests were used at pre- surgical and postsurgical assessments to minimise practice effects. An asterisk $\left.{ }^{\star}{ }^{\star}\right)$ denotes which tests were given in alternate versions. The test batteries containing alternate versions of the tests were coded A and B and were administered to the patients in counterbalanced fashion.

\section{Preoperative assessment}

All patients were assessed during their hospital admission 2 days before the STN procedure. The patients were tested during an "on" phase and while taking their usual medication.

\section{Postoperative assessment}

All patients were reassessed on the test battery when they returned to the hospital for an inpatient review by the team. This occurred a minimum of 3.5 months after surgery with the longest follow up time being 12 months. The vagaries of clinical and hospital practice were responsible for the variation in follow up periods. The mean time after surgery was 6.4 months. This period is considered sufficient to minimise potential inflation of scores postsurgery due to practice effects on those tests not available in alternate form. A period of greater than 12 months after surgery may have resulted in decrements in test performance due to progression of the disease process rather than disclosing potential deficits due to surgery. Again, all patients were tested "on" and while taking their usual medication. We were not able to control for alterations in medication after surgery as a consequence of the surgical outcome. All stimulators were functioning at the time of assessment.

\section{Results}

The estimated premorbid IQ of this group was relatively high with a mean NART-2 predicted IQ of 115 (range 106-27). Patients showed deficits, compared to published normative data, on several tests before surgery. Such a finding was expected in this patient group. The objective of our study was to identify any additional neuropsychological impairment that might reflect an effect of surgery. The data were analysed using tests of statistical significance and a reliable change index.

The mean presurgical and postsurgical test results for the group as a whole are presented in table 1. There were significant differences at $\mathrm{p}<0.05$ for three tests but the Bonferroni adjustment for multiple comparisons set the significance level at $\alpha=0.004$. No paired comparison was significant at this level. Two tests, facial recognition and release from proactive inhibition, were not analysed using the paired $t$ test. The scores for the facial recognition memory test were not normally distributed and were subject to non-parametric Wilcoxon signed ranks tests. There was no significant difference before and after surgery for the facial recognition test. The release from proactive inhibition test was scored as normal or abnormal. Eleven patients showed normal performance preoperatively and only six showed normal performance postoperatively. 
Table 1 Performance on neuropsychological tests before and after subthalamic neucleotomy

\begin{tabular}{lcccc}
\hline & $n$ & $\begin{array}{c}\text { Presurgical } \\
\text { (mean }(S D))\end{array}$ & $\begin{array}{c}\text { Postsurgical } \\
\text { (mean (SD)) }\end{array}$ & $p$ Value \\
\hline NART(a) & 12 & $115.25(7.98)$ & & \\
WAIS-R VIQ(b) & 12 & $107.00(12.40)$ & $110.17(13.83)$ & $0.04^{\star}$ \\
RAVLT Tr 1-5(c) & 11 & $39.55(9.17)$ & $39.27(9.90)$ & 0.93 \\
RAVLT Tr 6(c) & 11 & $8.00(3.19)$ & $7.73(3.90)$ & 0.76 \\
Story memory(d) immediate recall & 12 & $8.54(3.23)$ & $10.71(4.55)$ & $0.03^{\star}$ \\
Story memory(d) delayed recall & 12 & $7.63(3.16)$ & $8.63(4.24)$ & 0.28 \\
WMS-R A/C(e) & 11 & $102.27(15.07)$ & $99.00(12.54)$ & 0.21 \\
Stroop(f) & 10 & $82.60(27.27)$ & $75.50(24.69)$ & 0.17 \\
PASAT(g) & 9 & $33.89(11.58)$ & $28.67(15.39)$ & $0.03^{\star}$ \\
COWAT(h) & 12 & $39.92(14.27)$ & $39.92(13.30)$ & 1.00 \\
Burden balls(i) correct & 11 & $10.45(1.69)$ & $10.36(1.29)$ & 0.88 \\
Burden balls(i) time score & 11 & $76.82(13.84)$ & $78.18(11.87)$ & 0.71 \\
Design fluency(j) total & 11 & $20.18(10.94)$ & $18.09(9.13)$ & 0.18 \\
Design fluency(j) perseverations & 11 & $3.55(6.55)$ & $4.18(6.87)$ & 0.67 \\
†Facial recognition(k) & 12 & & & 1.00 \\
†RPI(l) & 12 & $11 / 12$ Normal & $6 / 12$ Normal & \\
\hline
\end{tabular}

${ }^{\star} \mathrm{p}<0.05$.

$\dagger$ Facial recognition pre/post surgery comparison on Wilcoxon signed ranks test non-significant. $¥$ Release from proactive inhibition $92 \%$ patients normal presurgery, $50 \%$ patients normal postsurgery.

(a) National adult reading test-2nd edition - predicted full scale IQ (presurgery only); (b) Wechsler adult intelligence scale-revised - verbal IQ (four item short form); (c) Rey auditory verbal learning test-total words trials 1-5 and retrieval trial 6 ; (d) Rivermead behavioural memory test story memory- immediate recall and delayed recall; (e) Wechsler memory scale-revisedattention/concentration index; (f) Stroop neuropsychological screening test-total colour/word; (g) paced auditory serial addition task-total at 2 second pacing; (h) controlled oral word association test-total words; (i) Burden balls-total correct and time to completion score;(j) design fluency- total designs and total perseverations; (k) Rivermead behavioural memory test facial recognition; (1) release from proactive inhibition.

In this study a priori assumptions about the effect of surgery on cognitive performance could not be confidently made, hence the use of many measures. Although the Bonferroni adjustment guards against the risk of capitalising on chance differences when making multiple comparisons in repeat testing, it may also increase the risk of a type 2 error-namely, accepting the null hypothesis when it is in fact false. Further, reliance solely on statistically significant difference ( $\mathrm{p}$ ) as a measure of "effect" in neuropsychological studies is flawed as it does not take into account the potential degree of overlap between two samples. Large study samples may show a statistically significant difference which may be clinically meaningless although smaller samples may produce statistically non-significant results but show large effect sizes, or magnitudes of discriminability which are clinically meaningful..$^{51}{ }^{52}$ Previous reports of outcome after surgery in Parkinson's disease have suggested heterogeneity with some patients showing a significant decline on tests which may be masked by comparison of group means. ${ }^{31} 32$ For these reasons, in addition to the grouped parametric statistics, we com-

Table 2 Percentage of test scores showing reliable change or no change postsurgery

\begin{tabular}{llccc}
\hline Patient & Operative procedure & $\begin{array}{l}\text { \% Reliable } \\
\text { improvement }\end{array}$ & $\begin{array}{l}\text { \% Reliable } \\
\text { deterioration }\end{array}$ & $\begin{array}{c}\% \text { No } \\
\text { change }\end{array}$ \\
\hline 1 & R STN & 7 & 0 & 93 \\
2 & R STN & 0 & 0 & 100 \\
3 & R STN & 38 & 0 & 62 \\
4 & R STN+L subthal stim & 0 & 23 & 77 \\
5 & R STN+L subthal stim & 0 & 25 & 75 \\
6 & R STN+L subthal stim & 13 & 0 & 87 \\
7 & R STN+L subthal stim & 0 & 0 & 67 \\
8 & L STN & 0 & 33 & 67 \\
9 & L STN & 0 & 33 & 80 \\
10 & Bilateral STN & 7 & 7 & 60 \\
11 & Bilateral STN & 13 & 13 & \\
12 & Bilateral STN & 27 & 700 \\
\hline
\end{tabular}

R STN=Unilateral right subthalamic nucleus ablation; L STN=unilateral left subthalamic nucleus ablation; R STN+L subthal stim=right subthalamic nucleus ablation plus left subthalamic nucleus stimulator; Bilateral STN=bilateral subthalamic nucleus ablations. pared the presurgical and postsurgical results of each patient's performance on each test to evaluate whether there were any indications of reliable change across surgery. Table 2 shows lesion type and percentages of scores showing reliable change presurgery to postsurgery.

Reliable change was calculated according to the formula first developed by Jacobson and Truax. ${ }^{53}$ This method has been used increasingly in the evaluation of presurgical to postsurgical neuropsychological change as a more robust and clinically meaningful measure than small yet statistically significant group differences. ${ }^{31} 36$ 44-47 54-58 The reliable change index is a standardised difference score. The significance of change in any one test score is based on the difference between the initial and retest scores for the normative subject sample. The change is considered to be reliable, and unlikely to have occurred by chance, if it exceeds the standard deviation of test-retest differences in the normative sample multiplied by the $z$ score cut point designating the 95th percentile of the normal distribution. For a two tailed comparison this is equal to 1.645 and should capture $90 \%$ of scores. The formula for calculating the reliable change index (RCI) is:

$$
R C I=\frac{x_{2}-x_{1}}{S_{\text {diff }}}
$$

Where $\mathbf{x}_{1}$ is the participant's first test score, $\mathrm{x}_{2}$ is their retest score, and $S_{\text {diff }}$ is the standard error of difference:

$$
S_{\text {diff }}=\sqrt{2\left(S_{E}\right)}
$$

The $S_{E}$ (standard error of measurement) is calculated using the SD of the control group, the normal population or pretreatment experiment group.

In this study, we used the published normative data for each test where available, using the relevant age and education subgroups. When these were not available we used the preoperative group means and SD for our patients (Burden balls, five point design fluency). The release from proactive inhibition data is excluded from this analysis as a reliable change index could not be generated from the scoring system used. Results from the reliable change analyses are illustrated in tables 2 and 3. Most patients showed no reliable change on most tests after STN surgery; $77 \%$ of test scores showed no reliable change, $9 \%$ showed reliable improvement, with only $12 \%$ of the total number of test scores showing any reliable deterioration.

Although the number of patients in this study is few, precluding detailed statistical analysis, some interesting trends in the data are worth noting. Inspection of the reliable change data shows that some patients scored worse on specific measures. The patients with unilateral right STN, as a group, showed deterioration in merely $2 \%$ of the total scores (RPI). Rates of reliably lower scores postoperatively were higher for patients with bilateral lesions, left lesions, or right STN plus additional left 
Table 3 Percentage of test scores showing reliable deterioration by test and operative procedure

\begin{tabular}{|c|c|c|c|c|c|}
\hline Test & $\begin{array}{l}\text { Bilateral } \\
\text { STN }\end{array}$ & $L S T N$ & $R S T N$ & $\begin{array}{l}\text { R STN+L } \\
\text { Subthal STIM }\end{array}$ & Total \\
\hline WAIS-R VIQ & 0 & 0 & 0 & 0 & 0 \\
\hline Design fluency total & 0 & 0 & 0 & 0 & 0 \\
\hline Design fluency perseverations & 0 & 0 & 0 & 0 & 0 \\
\hline Story memory immediate recall & 0 & 0 & 0 & 0 & 0 \\
\hline Story memory delayed recall & 0 & 0 & 0 & 0 & 0 \\
\hline Facial recognition & 0 & 50 & 0 & 0 & 9 \\
\hline COWAT & 33 & 0 & 0 & 0 & 9 \\
\hline WMS-R A/C & 0 & 50 & 0 & 33 & 19 \\
\hline STROOP & 0 & 100 & 0 & 33 & 30 \\
\hline PASAT & 0 & 0 & 0 & 33 & 11 \\
\hline RAVLT Tr $1-5$ total & 0 & 100 & 0 & 33 & 28 \\
\hline RAVLT Tr 6 & 0 & 50 & 0 & 33 & 19 \\
\hline Burden balls correct & 33 & 100 & 0 & 0 & 28 \\
\hline Burden balls time score & 33 & 0 & 0 & 0 & 9 \\
\hline
\end{tabular}

Percentages are rounded up. surprising given that the subthalamic nucleus has not previously been shown to play a direct role in cognition and the lesions made in our patients were small and meticulously placed using image guidance. However, there were some tests which did show deterioration for some patients.

Tests which did not show reliable deterioration in a significant number of patients included tests of verbal intelligence, contextual verbal memory, and fluency tasks. Measures of verbal intelligence tend to tap "crystallised" skills and this is thought to account for the relative resilience of verbal IQ even after severe diffuse brain injury (see Lezak ${ }^{59}$ for review). Contextual memory, as measured by recall of short stories, is not generally held to be differentially sensitive to frontal lobe or subcortical damage, although it may be disrupted by temporal lobe damage. Previous studies of pallidotomy have not found story recall to be impaired after the procedure. ${ }^{32} 33$ The preservation of phonemic verbal fluency has been previously reported after posteroventral pallidotomy. ${ }^{33}$ Improvements in motor function as a result of the surgery could have improved performance on the five point design fluency task resulting in simple output efficiencies masquerading as improved cognitive function, or masking subtle deterioration at a cognitive level. No patients deteriorated on total number of designs produced. However, there were no deteriorations either in number of perseverative designs-potentially a more sensitive measure of frontal disinhibition or cognitive impairment - on this test.

For those tests which did show reliable deterioration, this occurred more often in those patients with left sided procedures. The patients with left ablation (left STN and bilateral STN) and to some extent the patients with right ablation with a working left sided subthalamic nucleus stimulator, deteriorated on more measures of planning, spatial working memory, verbal memory, and attention which are thought to have an executive component. The STROOP and RAVLT have previously been reported as sensitive to left hemispheric dysfunction (see Lezak and Spreen and Strauss ${ }^{59}{ }^{60}$ ). The STROOP has not previously been found to be vulnerable to pallidotomy. ${ }^{232429}$ Our finding of deterioration in the verbal list learning task (RAVLT) for patients with left sided procedures but not right sided ablations is consistent with the results for posteroventral pallidotomy reported by Trepanier et al. ${ }^{31}$ The thalamus is known to be involved in memory processes with the dorsomedial nucleus of the thalamus most often cited as important to memory integrity, ${ }^{61-63}$ although there have been case reports of amnestic deficit after damage to other thalamic nuclei. ${ }^{64}$ It is possible that surgical ablation of the subthalamic nucleus may be detrimental to memory functions either as a result of alterations in the excitation and inhibition of a more extensive corticothalamic or mamillothalamic circuit or as an iatrogenic effect of the surgical procedure. The Burden balls, an adaptation of the Tower of London test, deteriorated post- 
operatively only for those patients with left ablations. This is a multicomponent test which is thought to tap spatial working memory, impulse control, verbal regulation of behaviour, and planning. ${ }^{4965}$ The Tower of London test has been found to be sensitive to impairments in frontal neural circuits, particularly prefrontal, cingulate, and premotor cortices, although parietal and occipital cortices are also activated during the task. ${ }^{65}$ In patients with Parkinson's disease, differential activation of the right globus pallidus interna compared with control subjects has been found during the Tower of London test, perhaps affecting the expression of prefrontal functions by disruption of the normal transmission of information through the frontostriatal circuitry. ${ }^{15}$ The release from proactive inhibition test deteriorated for a significant number of patients regardless of side of the lesion. This test is also thought to be reliant on frontal circuitry which may involve the basal ganglia, the thalamus in particular. Impaired release from proactive inhibition ${ }^{66}$ has been noted in amnesic disorders in which damage to the thalamus, mamillary bodies, and frontaldiencephalic connections are present but not in amnesias where the primary damage is in the mesial temporal lobes. ${ }^{67} 68$

We suggest, from these results, that subthalamic nucleotomy does not have global adverse cognitive consequences but it is possible that such procedures may produce discrete neuropsychological impairment in some patients. Aspects of verbal learning, attention, and planning, all of which are thought to involve an executive component and relate to frontostriatal neural circuits or frontothalamomammillary circuits, may prove vulnerable to disruption after STN due to interruption of complex information processing reliant on local circuits. Our data raise the possibility of differential vulnerability of the left and right hemispheres to this procedure. We acknowledge that the results of this study represent preliminary data on only a few patients and require replication in a larger study.

This patient group poses considerable difficulties for neuropsychological study. The motor symptoms are very debilitating, there is considerable variation in motivation and levels of fatigue in "on" and "off" states which can influence participation in cognitive assessment, and variations in general function as a consequence of medication schedules may produce variability in test performance within and across test sessions. The time after surgery was less than 12 months for our patients but it does remain possible that further progression of the Parkinson's disease process could have produced subtle deterioration in some functions for some patients. We did not have a no surgery control group for comparison. Use of the reliable change index, although robust for normal patients and reported as reliable for clinical groups in other published studies, ${ }^{54} 55$ is affected by neuropsychological competence at baseline.$^{69}$ Significantly impaired performance was found on some measures for our patients before surgery which may limit the applicability of reliable change scores to measurement of deterioration after surgery. Notwithstanding these limitations, our data suggest the possibility that operative procedures in the subthalamic nucleus may affect performance. Consideration of patient selection and decisions on the choice of ablations or stimulation may be informed by results of neuropsychological assessment and further study of the cognitive outcome of these procedures. The deficits seen in our patients were noted on complex and detailed neuropsychological assessment and correspond with current theories on the role of the basal ganglia in cognitive processes. Such deficits are not likely to be disclosed during routine neurological examination or by less complex cognitive assessments such as the mini mental state examination. Informed consent for an operation which is designed to reduce disabling and distressing motor symptoms needs to take into account potential cognitive costs.

This work was conducted as part of the clinical management of patients with Parkinson's disease at Frenchay Hospital, Bristol. We would like to acknowledge the assistance of Mr M Bunnage.

1 Hirai T, Miyazaki M, Nakajima $\mathrm{H}$, et al. The correlation between tremor characteristics and the predicted volume of effective lesions in stereotaxic nucleus ventralis intermedius thalamotomy. Brain 1983;106:1001-118.

2 Laitinen LV, Hariz MI. Leksell's posteroventral pallidotomy in the treatment of Parkinson's disease. $\mathcal{F}$ Neurosurg 1992;76:53-61

3 Dogali M, Fazzini E, Kolodny E, et al. Stereotactic ventral pallidotomy for Parkinson's disease. Neurology 1995;45: 753-61.

4 Johansson F, Malm J, Nordh E, et al. Usefulness of pallidotomy in advanced Parkinson's disease. $\mathcal{F}$ Neurol Neupasurg Psychiatry 1997;62:125-32.

5 Samii A, Turnbull IM, Kishore A, et al. Reassessment of Samil A, Turnbull IM, Kishore A, et al. Reassessment of
unilateral pallidotomy in Parkinson's disease: a two year follow up study. Brain 1999;122:417-25.

6 Limousin P, Pollak P, Benazzouz A, et al. Effect on Parkinsonian signs and symptoms of bilateral subthalamic nucleus stimulation. Lancet 1995;345:91-5.

7 Obeso JA, Alvarez LM, Macias RJ, et al. Lesion of the subthalamic nucleus in Parkinson's disease. Neurology 1997; 48:A138.

8 Gill SS, Heywood P. Bilateral dorsolateral subthalamotomy for advanced Parkinson's disease. Lancet 1997;350:1224.

9 Alexander GE, De Long MR, Strick PL. Parallel organisation of functionally segregated circuits linking basal ganglia and cortex. Annu Rev Neurosci 1986;9:357-81.

10 Afif AK. Basal ganglia: functional anatomy and physiology. Part 2 [review]. F Child Neurol 1993;9:352-61.

11 Brown RG, Marsden CD. Visuospatial function in ParkinBrown RG, Marsden CD. Visuospatial func
son's disease. Brain 1986;109:987-1002.

12 DellaSalla S, DiLorenzo G, Giordana A, et al. Is there a specific visuo-spatial impairment in Parkinson's disease. $\mathcal{F}$ Neurol Neurosurg Psychiatry 1986;49:1258-69.

13 Stern Y, Sano M, Mayeaux R. Comparisons of dementia and intellectual change in Parkinson's and Alzheimer's disease. Fournal of Clinical and Experimental Psychology 1987;9: 66.

14 Raskin S, Sliwinski M, Borod J. Verbal fluency in Parkinson's disease. F Clin Exp Neuropsychol 1989;11:92.

15 Owen AM, Doyon J, Dagher A, et al. Abnormal basal ganglia outflow in Parkinson's disease identified with PET. Implications for higher cortical functions. Brain 1998;121: 949-65.

16 ElAwar M, Becker JT, Hammond KM, et al. Learning deficit in Parkinson's disease: a comparison with Alzheimer's cit in Parkinson's disease: a comparison with Alzheim
disease and normal aging. Arch Neurol 1987;44:180-4.

17 Iverson SD, Mishkin M. Perseverative interference in monkeys following selective lesions of the inferior prefrontal circuitry. Exp Brain Res 1970;11:376-86.

18 Oberg RGE, Divac I. Levels of motor planning. Cognition and the control of movement. Trends Neurosci 1981;4:1224.

19 Butters N, Butter C, Rosen J, et al. Behavioural effects of sequential and one-stage ablations of orbital prefrontal cortex in the monkey. Exp Neurol 1973;39:204-14.

20 Fuster J. Unit activity in the prefrontal cortex during delayed response performance: neuronal correlates of transient memory. f Neurophysiol 1973;36:61-8.

21 Divac I, Rosvold HE, Szwarcbart MY., Behavioural effects of selective ablation of the caudate nucleus. Fournal of Comof selective ablation of the caudate nucleus. Fournal
parative Physiology and Psychology 1967;63:184-90.

22 Mishkin M, Manning FJ. Non-spatial memory after Mishkin M, Manning FJ. Non-spatial memory after
selective prefrontal lesions in monkeys. Brain Res 1978;143: selective 
23 Perrine K, Dogali M, Fazzini E, et al. Cognitive functioning after pallidotomy for refractory Parkinson's disease. $7 \mathrm{Neu}$ after pallidotomy for refractory Parkinso

24 Masterman D, DeSalles A, Baloh RW, et al. Motor, cognitive and behavioural performance following unilateral ventroposterior pallidotomy for Parkinson's disease. Arch Neurol 1998;55:1201-8.

25 Samra K, Riklan M, Levita E, et al. Language and speech correlates of anatomically verified lesions in thalamic surgery for parkinsonism. $\mathcal{F}$ Speech Lang Hear Res 1969;12 $510-40$.

26 Selby G. Stereotactic surgery for the relief of Parkinson's disease II. Analysis of the results of a series of 303 patients (413 operations). 7 Neurol Sci 1967;5:343-75.

27 Cullum CM, Laaritz LH, Frol AB, et al. Effects of pallidotomy on cognitive function in Parkinson's disease [abstract]. Fournal of the International Neuropsychological Society 1997;3:61.

28 Troster AL, Fields,JA, Wilkinson SB, et al. Changes in cognitive functions following unilateral thalamic VIM nucleus stimulator implantation for pharmacotherapy resistant stimulator implantation for pharmacotherapy resistant
Parkinson's disease: some preliminary observations [abParkinson's disease: some preliminary observations [ab-
stract]. Fournal of the International Neuropsychological Society stract]. Four

29 Lund-Johansen M, Hugdahl K, Wester K. Cognitive functioning in patients with Parkinson's disease undergoing stereotaxic thalamotomy. I Neurol Neurosurg Psychiatry 1996;60:564-71.

30 Soukup VM, Ingram F, Schiess MC, et al. Cognitive sequelae of unilateral posteroventral pallidotomy. Arch Neurol 1997;54:947-50

31 Trepanier LL, Saint-Cyr JA, Lozano AM, et al. Neurosychological consequences of posteroventral pallidotomy for the treatment of Parkinson's disease. Neurology 1998;51:207 15.

32 Troster AL, Fields JA, Wilkinson SB, et al. Unilateral pallidal stimulation for Parkinson's disease: neurobehavioural functioning before and three months after electrode functioning before and three months
implantation. Neurology 1997;49:1078-83.

33 Scott R, Gregory R, Hines N, et al. Neuropsychological, neurological, and functional outcome following palli-
dotomy for Parkinson's disease: a consecutive series of dotomy for Parkinson's disease: a consecutive series of eight simultaneous bilateral and

34 Cahn DA, Sullivan EV, Shear PK, et al. Neuropsychological and motor functioning after unilateral anatomically guided posterior ventral pallidotomy. Preoperative performance and 3 month follow-up. Neuropsychology and Behavioural Neurology 1998;11:138-45.

35 Hugdahl K, Wester K. Lateralised thalamic stimulation: effects on verbal memory. Neuropsychiatry Neuropsychology and Behavioural Neurology 1997;10:155-61.

36 Fields JA, Troster AI, Wilkinson SB, et al. Preliminary observations of effects on cognitive function following unilateral stimulating electrode implantation in globus pallidus internal (Gpi) for treatment of refractory Parkinson's disease [abstract]. Fournal of the International Neuropsychological Society 1997;3:67.

37 Green J, Viter JL, Bakay RAE, et al. Pallidotomy for treatment of Parkinson's disease: preliminary neuropsychoogical findings [abstract].Fournal of the International Neuropsychological Society 1997;3:67.

38 Maeshima S, Nakai K, Nakai E, et al. Effects on cognitive function and activity of daily living after stereotactic thalamotomy for Parkinson's disease [abstract]. No Shinkei Geka 1995;23:417-21.

39 Gross RE, Lombardi WJ, Lang AE, et al. Relationship of lesion location to clinical outcome following microelectrode-guided pallidotomy for Parkinson's disease. Brain 1999;122:405-16.

40 Nelson $\mathrm{H}$, Willison J. National adult reading test (NART): test manual. 2nd ed. Windsor, England: NFER Nelson, 1991.

41 Wechsler D. Wechsler adult intelligence scale: revised (WAIS-R) manual. New York: The Psychological Corporation, 1981.

42 Lezak M D. Neuropsychological assessment. 2nd ed. New York: Oxford University Press, 1983.

43 Wilson B, Cockburn J, Baddeley A, et al. Rivermead behavioural memory test, 2 nd ed. Bury St Edmunds: Thames Valley Test Company, 1991.
44 Wechsler D. Wechsler memory scale revised (WMS-R) manual. New York: The Psychological Corporation, 1987.

45 Trenerry MR, Crosson B, CeBoe J, et al. Stroop neuropsychological screening test manual. Odessa, Florida: Psychological Assessment Resources 1989.

46 Gronwall DMA. Paced auditory serial addition task: a measure of recovery from concussion. Percept Mot Skills 1977;44:367-73

47 Spreen O, Benton AL. Neurosensory center comprehensive examination for aphasia (NCCEA). Victoria: University of Victoria Neuropsychology Laboratory, 1969.

48 Regard M. The perception and control of emotions: hemispheric differences and the role of the frontal lobes. Habilitationsschrift. Zurich: University Hospital Department of Neurology, 1991.

49 Shallice T. Specific impairments of planning. Transcripts of the Royal Society of London 1982;298:199-209.

50 Anderson P, Anderson V, Lajoi G. The Tower of London test: validation and standardization for paediatric populations. Clinical Neuropsychologist 1996;10:54-65.

51 Zakzanis KK. Brain is related to behaviour $(\mathrm{p}<0.05)$. 7 Clin Exp Neuropsychol 1998;20:419-27.

52 Bieliauskas LA, Fastenau PS, Lacey MA, et al. Use of the odds-ratio to translate neuropsychological test scores into real-world outcomes: from statistical significance to clinical significance. F Clin Exp Neuropsychol 1997;19:889-96.

53 Jacobson NS, Truax P. Clinical significance: a statistical approach to defining meaningful change in psychotherapy research. F Consult Clin Psychol 1991;59:12-19.

54 Chelune J, Naugle RI, Luders H, et al. Individual change after epilepsy surgery: practice effects and baserate information. Neuropsychology 1993;7:41.

55 Hinton-Bayre AD, Geffen GM, Geffen LB, et al. Concussion in contact sport: reliable change indices of impairment and recovery. F Clin Exp Neuropsychol 1999;21:70-86.

56 Walton NH, Goodsman C, McCarter RJ, et al. An analysis of neuropsychological change scores following selective temporal resection of the non-dominant temporal lobe. Seizure $1999 \cdot 8 \cdot 241-5$.

57 Phillips NA, McGlone J. Grouped data do not tell the whole story: individual analysis of cognitive change after temporal lobectomy. F Clin Exp Neuropsychol 1995;17:713-24.

58 Hermann BP, Wyler AR. Neuropsychological outcome of anterior temporal lobectomy. Fournal of Epilepsy 1988;1: $35-45$.

59 Lezak M. Neuropsychological assessment. 3rd ed. New York: Oxford University Press, 1995

60 Spreen O, Strauss E. A compendium of neuropsychological tests. 2nd ed. New York: Oxford University Press, 1998.

61 Aggleton JP, Mishkin M. Memory impairments following restricted medical thalamic lesions. Exp Brain Res 1983;52: 199-209.

62 Squire LR. The anatomy of amnesia. Trends Neurosci 1980; 3:52-4.

63 McEntee WJ, Biber MP, Perl DP, et al. Diencephalic amnesia; a reappraisal. I Neurol Neurosurg Psychiatry 1976; 39:436-41.

64 Stuss DT, Guberman A, Nelson R, et al. The neuropsychology of paramedian thalamic infarction. Brain Cogn 1988;8: 348-78.

65 Baker SC, Rogers RD, Owen AM, et al. Neural systems engaged by planning: A PET study of the Tower of London task. Neuropsychologia 1996;34:515-26.

66 Wickens DD. Encoding categories of words: an empirical approach to meaning. Psychol Rev 1970;77:1-15.

67 Cermak LS, Butters N, Moreines J. Some analyses of the verbal encoding deficit of alcoholic Korsakoff's patients. Brain Lang 1974;1:141-50.

68 Squire LR. Comparisons between forms of amnesia: some deficits are unique to Korsakoff's syndrome. $\mathcal{F}$ Exp Psychol Learn Mem Cogn 1982;8:560-71.

69 Temkin NR, Heaton RK, Grant I, et al. Detecting significant change in neuropsychologial test performance: a comparison of four models. Fournal of the International Neuropsychological Society 1999;5:357-69. 